\title{
Potential role of asymptomatic kitchen food handlers during a food-borne outbreak of norovirus infection, Dublin, Ireland, March 2009
}

N Nicolay (nathalienicolay@yahoo.fr) ${ }^{1,2}$, R McDermott ${ }^{3}$, M Kelly ${ }^{4}$, M Gorby ${ }^{4}$, T Prendergast $^{4}$, G Tuite ${ }^{5}$, S Coughlan ${ }^{5}$, P McKeown 1 , G Sayers ${ }^{3}$

1. Health Protection Surveillance Centre, Dublin, Ireland

2. European Programme for Intervention Epidemiology Training (EPIET), European Centre for Disease Prevention and Control (ECDC), Stockholm, Sweden

3. Department of Public Health, Health Service Executive, Dublin, Ireland

4. Environmental Health Office, Health Service Executive, Dublin, Ireland

5. National Virus Reference Laboratory (NVRL), Dublin, Ireland

Citation style for this article:

Nicolay N, McDermott R, Kelly M, Gorby M, Prendergast T, Tuite G, Coughlan S, McKeown P, Sayers G. Potential role of asymptomatic kitchen food handlers during a foodborne outbreak of norovirus infection, Dublin, Ireland, March 2009.

Euro Surveill. 2011;16(30):pii=19931. Available online: http://www.eurosurveillance.org/ViewArticle.aspx?Articleld=19931

In March 2009, the Department of Public Health in Dublin, Ireland, was notified of a cluster of four gastroenteritis cases among people who attended a family lunch in a Dublin hotel. A retrospective cohort study was carried out. An outbreak case was defined as an attendee who developed diarrhoea and/or vomiting in the 60 hours following the lunch. Of 57 respondents, 27 met the case definition. Consumption of egg mayonnaise, turkey with stuffing or chicken sandwiches were each associated with increased risk of gastroenteritis: (risk ratio (RR): 2.3 ; $95 \% \mathrm{Cl}: 1.4-3.9$ ), (RR: 1.9; 95\% Cl: 1.2-3.2), (RR: 1.9; $95 \% \mathrm{Cl}: 1.1-3.1$ ), respectively. An environmental investigation established that before notification of the cluster, there had been unreported gastroenteritis among staff at the hotel. The earliest symptomatic person identified was a staff member who had vomited in the staff toilets but had not reported it. The sandwiches had most likely been contaminated by three asymptomatic kitchen food handlers who had used the same toilets. Stool samples were submitted by eight cases and 10 staff members. All eight cases and three asymptomatic food handlers on duty at the lunch tested positive for norovirus genogroup II.4 2006. Our analysis suggests that asymptomatic food-handlers can be responsible for norovirus transmission.

\section{Introduction}

Norovirus causes self-limiting gastroenteritis that is usually characterised by sudden and abrupt vomiting followed by more prolonged diarrhoea [1]. A low infectious dose, a capacity to survive long periods in the environment, thermal stability and resistance to many common disinfectants contribute to the considerable outbreak potential of this virus [2]. Transmission primarily occurs through environmental contamination following direct soiling and indirect aerosolisation resulting from projectile vomiting. It can be introduced into a particular setting by contaminated drinking water or food [3]. Subsequent person-to-person transmission will lead to onward propagation in the original setting or in other linked settings, often making the original contamination event difficult to identify [4]. It is important to investigate outbreaks due to norovirus in order to ascertain the source of the infection and mode of transmission. However, finding the initial event that allows the linkage of cases is often problematic, making the epidemiological investigation challenging [5]. Immunity against norovirus occurs post infection but may be short lived. This, plus the existence of several viral antigenic types, means later re-infection is possible [2].

In Ireland, individual cases as well as outbreaks of norovirus infection have been legally notifiable since 2004 (Infectious Diseases (Amendment) (No. 3) Regulations 2003). Norovirus caused 115 outbreaks - $48 \%$ of outbreaks of infectious intestinal disease in Ireland in 2009 [6]. In March 2009, the Department of Public Health in Dublin, was informed by local environmental health officers of four gastroenteritis cases. Environmental health officers initially interviewed the informant, a family member who had organised the event. The person indicated that all cases had attended an extended-family lunch three days earlier: 100 family and friends attended the lunch in a hotel in Dublin. The menu consisted of soup, a variety of handmade sandwiches (egg mayonnaise, tuna mayonnaise, ham, salad, turkey with stuffing, chicken and cheese), followed by tea or coffee. Guests were free to help themselves from communal platters. The food was prepared by five kitchen food handlers. There was no history of illness among the guests prior to the family function. The guests attended a church service before the lunch. Apart from family groupings, there had been no gathering of guests before that day. Given the clustering of people with symptoms, the hotel was suspected as the location of exposure and food served at the hotel the 
vehicle of contamination. A multidisciplinary outbreak control team was established: this report describes the epidemiological investigation that was carried out to determine the extent of the outbreak, to identify the aetiological agent and mode of transmission and to take appropriate control measures.

\section{Methods}

\section{Study design}

A retrospective cohort study was carried out among attendees at the lunch. As no list of the guests was available, active participant finding was facilitated by the organiser of the lunch. Each respondent was asked to provide contact details for all other attendees known to them. Every person identified was contacted and interviewed.

Using a standardised structured questionnaire, food and beverage consumption was assessed, as well as exposure to any person with diarrhoea (defined as three or more loose stools per day) or vomiting in the week before the lunch. Environmental health officers administered the questionnaire by telephone, from day 3 to day 6 after the lunch. Information on sociodemographic characteristics of the respondents and the spectrum of symptoms was also recorded.

\section{Case definition}

An outbreak case was defined as a lunch attendee who developed diarrhoea (defined as three or more loose stools per day) or vomiting or both during the 60 hours following the lunch.

\section{Environmental investigation}

Local environmental health officers inspected the hotel on the day they were notified of the cluster of illness (three days after the lunch). Staff on duty for the lunch and any staff who reported any gastrointestinal symptoms one week before and/or after the lunch were interviewed.

An environmental assessment was undertaken at the hotel, as well as a review of work practices including the Hazard Analysis and Critical Control Points (HACCP) system [7]. The inspection included sampling of food items (e.g. sliced turkey and ham used for sandwiches on the day of the event), mains water and ice. The food items were tested for indicator bacteria (aerobic colony count), Salmonella spp. and Escherichia coli and toxins of Staphylococcus aureus, Bacillus cereus and Clostridium perfringens. Water samples were taken from the bar and the kitchen at the hotel and tested for indicator bacteria (coliforms, E. coli and Enterococcus spp.). Ice samples were also tested for coliforms, E. coli and Enterococcus spp.

\section{Clinical microbiological investigation}

Following notification of the outbreak, stool samples were collected from eight cases, from the five food handlers responsible for the sandwich preparation, and any staff members who reported having had gastrointestinal illness one week before and up to one week after the lunch. Faecal specimens were tested for Salmonella spp., Shigella, Campylobacter and enterohaemorrhagic E. coli. and for the toxins of $C$. perfringens, S. aureus and B. cereus. They were also examined for norovirus by reverse transcriptionpolymerase chain reaction (RT-PCR) $[8,9]$. The DNA sequences were analysed using SeqMan and CLUSTAL W. Genotype information was obtained by comparing the sequences against those available in GenBank using BLAST. Rotavirus was not tested for as this outbreak mainly involved adults.

\section{Statistical analysis}

A data matrix was constructed in EpiData Entry version 2.0 software (EpiData Association, Denmark) and analysis undertaken using Stata version 9.0 (StataCorp LP, United States). Age according to illness status was compared using Student's t-test Specific attack rates (ARs) and crude risk ratios (RRs) with 95\% confidence intervals (Cls) were calculated according to the sex of those affected and for each specific food and beverage exposure. Research of effect modifier was performed using stratified analysis by variable of exposure.

\section{Results}

\section{Epidemiological investigation}

The cohort study recruited 57 attendees who completed the questionnaire, out of a total of 100 attendees (response rate: $57 \%$ ). Of these, 27 met the case definition (AR: 47\%). One attendee presented with symptoms more than 72 hours after the lunch and was considered as a secondary case and was excluded from the cohort study.

The median age of cases was 51 years (range: 13-87) and the median age of attendees who were not cases $(n=30)$ was 47 years (range: $11-78)$. Among the cases, 11 were male and among those who were not cases, 14

\section{FIGURE}

Outbreak cases due to norovirus infection, family lunch, Dublin, Ireland, March $2009(n=26)^{a}$

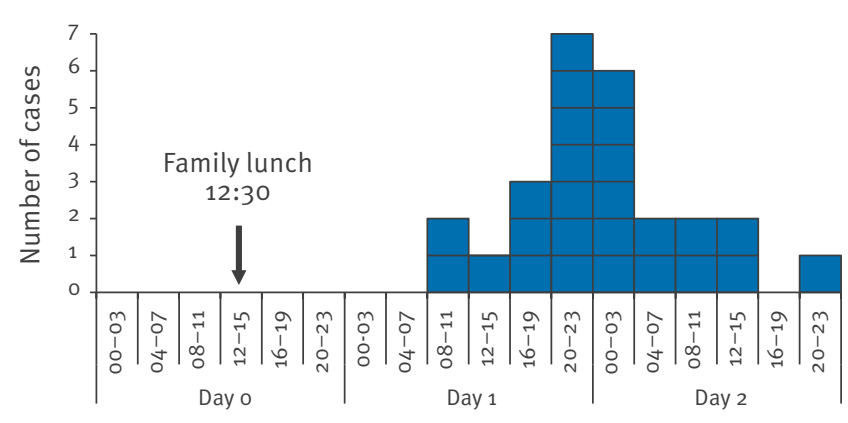

Day and full hour of symptom onset (March 2009)

${ }^{a}$ One case was unable to recall the exact time of symptom onset. 
were male. The differences in median age and proportion of cases who were male in the two groups were not statistically significant.

The time of symptom onset ranged from less than 24 hours to 60 hours after the lunch. The epidemic curve showed a peak in the number of cases between 28 hours and 44 hours after the lunch (Figure).

All cases reported diarrhoea; 16 cases reported vomiting. Additionally, 18 cases reported nausea, 15 abdominal pain, 11 chills, 10 headache, nine reported fever and seven reported muscle pain. The median duration of acute symptoms was 44 hours (range: 3-72). Two cases consulted their general practitioner following the occurrence of symptoms; none were hospitalised.

In a univariate analysis (Table), cases who reported eating egg mayonnaise sandwiches (AR: $78 \%$ exposed vs $33 \%$ not exposed) were associated with the highest risk of gastroenteritis (RR: $2.3,95 \% \mathrm{Cl}: 1.4-3.9$ ). Eating turkey stuffing sandwiches ( $73 \%$ vs $38 \%$ ) or chicken sandwiches (67\% vs $36 \%$ ) was associated with an increased risk of gastroenteritis (RR: $1.9 ; 95 \%$ $\mathrm{Cl}$ : 1.2-3.2), (RR: 1.9; 95\% Cl: 1.1-3.1), respectively. Eating cheese sandwiches (65\% vs $35 \%$ ) was marginally associated with an increased risk of gastroenteritis (RR: $1.8 ; 95 \% \mathrm{Cl}: 1.0-3.2$ ). Consumption of salad, tuna mayonnaise or ham sandwiches were not associated with illness. No significant association was found between the consumption of beverages and gastroenteritis.
We then carried out an analysis stratified by consumption of each sandwich type. Eating of chicken was significantly associated with an increased risk of gastroenteritis in attendees who had not eaten turkey with stuffing (RR: $3.3 ; 95 \% \mathrm{Cl}: 1.5-7.3 ; \mathrm{p}=0.002$ ), but was not in attendees who had eaten turkey with stuffing (RR: $0.6 ; 95 \% \mathrm{Cl}: 0.3-1.3 ; \mathrm{p}=0.18$ ). No other association was found.

\section{Environmental investigation}

A HACCP Food Safety Management System was in place in the hotel. Food appeared to be prepared in a safe and hygienic manner and the staff members were highly trained. No skin lesions were noted on food handlers during the inspection. Overall, the environmental health officers were of the opinion that the food premises were well managed.

All the food used in the sandwiches was freshly prepared at the hotel. The meats were cooked and cooled on the day before the lunch and were sliced on the function day. The preparation and cutting of the sandwiches took place just before and during the function. A variety of sandwiches were made on an ongoing basis, rather than in batches of one type and then another.

Five food handlers (Food handlers 1 to 5 ) had been allocated to prepare the sandwiches: all the food handlers prepared various types of sandwiches. Hotel staff mentioned that the attendees arrived earlier and in greater numbers than expected and that the five food handlers were under time pressure when preparing the

TABLE

Univariate analysis of risks associated with food and beverage consumption, family lunch, Dublin, Ireland, March 2009 (n=57)

\begin{tabular}{|c|c|c|c|c|c|c|c|c|}
\hline \multirow[b]{2}{*}{ Item tested } & \multicolumn{3}{|c|}{ Exposed } & \multicolumn{3}{|c|}{ Not exposed } & \multirow[b]{2}{*}{ Risk ratio } & \multirow[b]{2}{*}{$95 \% \mathrm{Cl}$} \\
\hline & $\begin{array}{l}\text { Total number } \\
\text { of attendees } \\
\text { exposed }\end{array}$ & $\begin{array}{c}\text { Number of } \\
\text { cases }\end{array}$ & $\begin{array}{c}\text { Attack rate } \\
(\%)\end{array}$ & $\begin{array}{l}\text { Total number } \\
\text { of attendees } \\
\text { not exposed }\end{array}$ & $\begin{array}{c}\text { Number of } \\
\text { cases }\end{array}$ & $\begin{array}{c}\text { Attack rate } \\
(\%)\end{array}$ & & \\
\hline \multicolumn{9}{|l|}{ Food } \\
\hline \multicolumn{9}{|l|}{ Sandwiches } \\
\hline Egg mayonnaise & 18 & 14 & 78 & 39 & 13 & 33 & 2.3 & $1.4-3.9$ \\
\hline $\begin{array}{l}\text { Turkey with } \\
\text { stuffing }\end{array}$ & 15 & 11 & 73 & 42 & 16 & 38 & 1.9 & $1.2-3.2$ \\
\hline Chicken & 21 & 14 & 67 & 36 & 13 & 36 & 1.9 & $1.1-3.1$ \\
\hline Cheese & 23 & 15 & 65 & 34 & 12 & 35 & 1.8 & $1.0-3.2$ \\
\hline Salad & 14 & 5 & 36 & 43 & 22 & 51 & 0.7 & $0.3-1.7$ \\
\hline $\begin{array}{l}\text { Tuna } \\
\text { mayonnaise }\end{array}$ & 18 & 10 & 56 & 39 & 17 & 44 & 1.3 & $0.7^{-2.2}$ \\
\hline Ham & 8 & 4 & 50 & 49 & 23 & 47 & 1.1 & $0.5-2.3$ \\
\hline Soup & 50 & 25 & 50 & 7 & 2 & 29 & 1.8 & $0.5-5.8$ \\
\hline \multicolumn{9}{|l|}{ Beverage } \\
\hline Mains water & 4 & 3 & 75 & 53 & 24 & 45 & 1.7 & $0.9-3.1$ \\
\hline Ice & 9 & 5 & 56 & 48 & 22 & 46 & 1.2 & $0.6-2.3$ \\
\hline Coffee & 15 & 6 & 40 & 42 & 21 & 50 & 0.8 & $0.4-1.6$ \\
\hline Tea & 30 & 15 & 50 & 27 & 12 & 44 & 1.1 & $0.7-2.0$ \\
\hline
\end{tabular}


sandwiches. The family lunch was the only function held in the hotel at lunchtime that day; another function was held that evening. Hotel staff contacted representatives of this party and no illness was reported in association with this event. No further cases of norovirus infection associated with the hotel were reported to the public health authorities around that time.

In-depth face-to-face interviews were conducted with the five food handlers during the inspection of the premises on day 3 after the lunch. They reported no gastrointestinal symptoms and had no known contact with a symptomatic person. They were employed full time on the premises and had worked full time the week before the lunch.

The on-site investigation by environmental health officers including face-to-face interviews with hotel management and staff (on day 3 after the lunch) indicated that there had been some symptoms of gastroenteritis among other staff who were off duty the day of the lunch.

One food handler (Food handler 6) had vomited in the staff toilets seven days before the lunch but had not reported this to the management at that time. This person was then off duty for 48 hours and had no involvement in the lunch. Another food handler (Food handler 7) developed gastrointestinal symptoms at home while off duty three days before the lunch and did not return to work before the lunch. Investigations by environmental health officers revealed that gastrointestinal symptoms had also occurred in some hotel staff not involved in food preparation: two bar workers had been symptomatic two days before the lunch while off duty and neither worked on the day of the lunch. A third bar worker became symptomatic one week after the lunch. This worker had not been present at the lunch and reported contact with a person with gastroenteritis in their own household before becoming symptomatic.

\section{Laboratory investigation}

Bacteriological analysis of all food, water and ice samples and of all clinical samples was negative.

Eight lunch attendees and the 10 relevant staff (Food handlers 1 to 7 and Bar workers 1 to 3 ) submitted stool samples (five to six days after the lunch). The samples from all eight attendees tested and five of the 10 staff were positive for norovirus RNA genogroup II.4 2006. The staff members who tested positive were three of the five asymptomatic food handlers (Food handlers 1 to 3) who were on duty at the lunch and two of the staff who had been symptomatic at home: a bar worker (Bar worker 2) and a food handler (Food handler 7). The staff member who had vomited on the premises seven days before the lunch tested negative (Food handler 6).

\section{Control measures}

Food-safety advice on preparation techniques, temperature control, risk analysis based on the HACCP system, and cleaning and personal hygiene, including hand washing, was given to all available staff members during the initial inspection on day 3 following the lunch. Staff and management were also given written advice on enteric precautions. The management were specifically advised to only use bought-in pre-prepared turkey, ham, chicken and egg mayonnaise, to minimise handling and shorten the preparation chain while the investigation was ongoing. Further advice on cleaning and decontamination of the hotel was also given.

As the hotel had good hygiene and cleaning management systems already in place, the environmental health officers initially considered that intensive decontamination of the premises by a specialist contractor was unnecessary. However, when the diagnosis of norovirus infection was confirmed, the hotel, including the gym and all bedrooms, was disinfected by a specialist contractor in accordance with national guidance [10].

\section{Discussion}

The epidemic curve of this outbreak suggested a single, common, point source and the cohort study identified several types of sandwiches served during the family lunch as possible vehicles of contamination, with egg mayonnaise, turkey with stuffing and chicken sandwiches being the most likely vehicles of the outbreak. Sandwiches (as a ready-to-eat food) are recognised to be potential vehicles for norovirus outbreaks $[3,11,12]$. Since a tiny inoculum (as few as 10 virus particles) is sufficient to cause infection [13], norovirus outbreaks can easily occur. The results of our study are consistent with previous reports where multi-ingredient foods were implicated in norovirus outbreaks [14,15]. The viral strain isolated in attendees and staff members was the commonly circulating strain in Ireland [16].

In the outbreak investigated here, the food handler who vomited in the staff toilets one week before the lunch was the earliest symptomatic person identified. The vomiting episode was not reported at the time and appropriate cleaning did not take place. Other staff members could have been infected via direct contact with fomites, such as the contaminated surfaces in the toilets, as has occurred in other outbreaks [17-20] Therefore, it is extremely important that staff report any vomiting episode and that it be managed as infectious [10]. A response team should immediately decontaminate and clean the area after the vomiting episode has occurred. Members of this team must not be food handlers. Hot water $\left(\geq 60^{\circ} \mathrm{C}\right)$ plus disinfectant such as $0.1 \%$ bleach solution should be used for the cleaning. Rapid implementation of such enhanced hygiene measures is the only way to prevent transmission via the environment [21].

In this outbreak, direct person-to-person transmission by the initial symptomatic person was possible but was probably limited, as this person left work soon after the vomiting episode. Transmission of the virus from 
contaminated kitchen surfaces was unlikely, given the cleaning schedule in place at the hotel (daily cleaning of all areas of the hotel, particularly the kitchen), which reduced the likelihood of the kitchen being a continuing source of norovirus contamination. Widespread contamination in the kitchen would have led to more cases among people who had eaten at the hotel. It is worth noting that no further cases of norovirus infection associated with the hotel were reported to the public health authorities around that time. The same facilities were used the same evening for another family party and there were no reports of gastrointestinal disease. It has been established that swabbing environmental surfaces is helpful in formally excluding their role in norovirus transmission [22]. However, the resources are not currently available in Ireland to carry out such investigations.

From our investigation, it would appear that asymptomatic food handler(s) contaminated sandwiches during their preparation. A Japanese study demonstrated that food handlers could be infected with norovirus without displaying any symptoms and could shed a similar number of virus particles as those who were symptomatic, which could potentially lead to widespread dissemination of the virus [23]. An outbreak investigation detected the presence of norovirus RNA on the hands of food handlers, which demonstrated the feasibility of norovirus transmission by virus-shedding food handlers [22]. Our investigation found three asymptomatic food handlers who tested positive for norovirus and who probably were the source of this outbreak at the lunch. The workers appeared to be highly trained, but the time pressure resulting from the early arrival and increased number of attendees is likely to have contributed to a lapse in personal hygiene before and during the ongoing preparation of sandwiches during the lunch, resulting in the contamination of the food. The handling of multiple foods by three asymptomatic carriers is reflected in the findings that several sandwich types were significantly associated with illness.

The response rate of $57 \%$ in our cohort study was less than optimal: there was no guest list for this function and, despite exhaustive efforts, it was not possible to interview all attendees. While we cannot rule out the introduction of bias due to this, we consider that a larger sample size would not alter the overall findings of this investigation that asymptomatic food handlers can cause a substantial norovirus outbreak.

It is impossible to obtain retrospectively objective confirmation of the absence of symptoms; however, the three asymptomatic food handlers always maintained that they had had no symptoms. They were interviewed by experienced professionals and appeared to be unembarrassed, very straightforward and truthful during their interview and provided stool samples without reservation. They were well informed about the risk of infection associated with gastroenteritis. The hotel was well run and the management and the staff were very compliant and cooperative throughout the course of investigation.

It is common practice in the leisure industry that staff members are not paid during periods of sick leave, which could act as a barrier to reporting; however, in Ireland, sick staff can claim a state allowance that covers their unpaid days.

In conclusion, our study indicates that asymptomatic food handlers who shed norovirus can be responsible for food-borne outbreaks particularly when preparing ready-to-eat foods during busy work periods in circumstances that potentially impede good personal hygiene. Such outbreaks involving food handlers should be prioritised for investigation by public health authorities in order to better estimate the burden of the illness due to asymptomatic carriers. This investigation highlights that any single vomiting episode should be immediately reported to the management in order to prevent spread of gastrointestinal illness.

\section{Acknowledgements}

We would like to thank Patricia Garvey for her critical scientific feedback, Dr Brian O'Herlihy, former Director of Public Health, and Dr Maire 0'Connor, Specialist in Public Health Medicine, Health Service Executive, for their advice and support in the investigation of this outbreak. We would like to thank the environmental health officers from the Communicable Disease Unit, Health Service Executive Dublin North East. We also wish to thank Dr Eleanor McNamara and the Public Health Laboratory, Cherry Orchard Dublin, for advice and technical support. We would like to thank Barbara Hennessy and Bernie Clarke for administrative support.

\section{References}

1. Rockx B, De Wit M, Vennema H, Vinjé J, de Bruin E, Van Duynhoven $Y$, et al. Natural history of human calicivirus infection: a prospective cohort study. Clin Infect Dis. 2002;35(3):246-53

2. Patel MM, Hall AJ, Vinjé J, Parashar UD. Noroviruses: a comprehensive review. J Clin Virol. 2009;44(1):1-8.

3. Baert L, Uyttendaele M, Stals A, VAN Coillie E, Dierick K, Debevere J, et al. Reported foodborne outbreaks due to noroviruses in Belgium: the link between food and patient investigations in an international context. Epidemiol Infect. 2009;137(3):316-25.

4. Verhoef L, Duizer E, Vennema H, Siebenga J, Swaan C, Isken $\mathrm{L}$, et al. Import of norovirus infections in the Netherlands and Ireland following pilgrimages to Lourdes, 2008--preliminary report. Euro Surveill. 2008;13(44):pii=19025. Available from: http://www.eurosurveillance.org/ViewArticle. aspx?Articleld $=19025$

5. Michel A, Fitzgerald R, Whyte D, Fitzgerald A, Beggan E, O'Connell N, et al. Norovirus outbreak associated with a hotel in the west of Ireland, 2006. Euro Surveill. 2007;12(7):pii=725. Available from: http://www.eurosurveillance.org/ViewArticle. aspx?Articleld $=725$

6. Health Protection Surveillance Centre (HPSC). Annual report 2009. Dublin: HPSC: 2010. Available from: http://www.hpsc.ie/ hpsc/AboutHPSC/AnnualReports/File,4751,en.pdf

7. Food Safety Authority of Ireland (FSAI). Guidance note. Assessment of HACCP compliance (Revision 2). FSAI: Dublin; 2007. Available from: http://www.fsai.ie/WorkArea/ DownloadAsset.aspx?id=738

8. Kageyama T, Kojima S, Shinohara M, Uchida K, Fukushi S, Hoshino FB, et al. Broadly reactive and highly sensitive assay for Norwalk-like viruses based on real-time quantitative reverse transcription-PCR. J Clin Microbiol. 2003;41(4):1548-57. 
9. Rolfe KJ, Parmar S, Mururi D, Wreghitt TG, Jalal H, Zhang H, et al. An internally controlled, one-step, real-time RT-PCR assay for norovirus detection and genogrouping. J Clin Virol. 2007;39(4):318-21.

10. Health Protection Surveillance Centre (HPSC). Guidance on the management of outbreaks of noroviral infection in tourist and leisure industry settings. October 2007. Dublin: HPSC. Available from: http://www.hpsc.ie/hpsc/A-Z/Gastroenteric/ Norovirus/Publications/File,2541,en.pdf

11. de Wit MA, Widdowson MA, Vennema H, de Bruin E, Fernandes T, Koopmans M. Large outbreak of norovirus: the baker who should have known better. J Infect. 2007;55(2):188-93.

12. Godoy P, Izcara J, Bartolomé R, Bach P, Escobar A, Pal M, et al. JOutbreak of food-borne norovirus associated with the consumption of sandwiches]. Med Clin (Barc). 2005;124(5):1614. Spanish.

13. de Wit MA, Koopmans MP, Kortbeek LM, Wannet WJ, Vinjé J, van Leusden F, et al. Sensor, a population-based cohort study on gastroenteritis in the Netherlands: incidence and etiology. Am J Epidemiol. 2001;154(7):666-74.

14. Greig JD, Todd EC, Bartleson CA, Michaels BS. Outbreaks where food workers have been implicated in the spread of foodborne disease. Part 1. Description of the problem, methods, and agents involved. J Food Prot. 2007;70(7):1752-61.

15. Vivancos R, Shroufi A, Sillis M, Aird H, Gallimore Cl, Myers L, et al. Food-related norovirus outbreak among people attending two barbeques: epidemiological, virological, and environmental investigation. Int J Infect Dis. 2009;13(5):629-35.

16. Waters A, Coughlan S, Dunford L, Hall WW. Molecular epidemiology of norovirus strains circulating in Ireland from 2003 to 2004. Epidemiol Infect. 2006;134(5):917-25.

17. Evans MR, Meldrum R, Lane W, Gardner D, Ribeiro CD, Gallimore $\mathrm{Cl}$, et al. An outbreak of viral gastroenteritis following environmental contamination at a concert hall. Epidemiol Infect. 2002;129(2):355-60.

18. Marks PJ, Vipond IB, Carlisle D, Deakin D, Fey RE, Caul EO. Evidence for airborne transmission of Norwalk-like virus (NLV) in a hotel restaurant. Epidemiol Infect. 2000;124(3):481-7.

19. Ho MS, Glass RI, Monroe SS, Madore HP, Stine S, Pinsky PF, et al. Viral gastroenteritis aboard a cruise ship. Lancet. 1989;2(8669):961-5.

20. Widdowson MA, Glass R, Monroe S, Beard RS, Bateman JW, Lurie P, et al. Probable transmission of norovirus on an airplane. JAMA. 2005;293(15):1859-60.

21. Heijne JC, Teunis P, Morroy G, Wijkmans C, Oostveen S, Duizer $\mathrm{E}$, et al. Enhanced hygiene measures and norovirus transmission during an outbreak. Emerg Infect Dis. 2009;15(1):24-30.

22. Boxman I, Dijkman R, Verhoef L, Maat A, van Dijk G, Vennema $\mathrm{H}$, et al. Norovirus on swabs taken from hands illustrate route of transmission: a case study. J Food Prot. 2009;72(8):1753-5.

23. Ozawa K, Oka T, Takeda N, Hansman GS. Norovirus infections in symptomatic and asymptomatic food handlers in Japan. J Clin Microbiol. 2007;45(12):3996-4005. 